University of Wollongong

Research Online

Faculty of Engineering and Information

Faculty of Engineering and Information

Sciences - Papers: Part A

Sciences

$1-1-2013$

Strengthening square reinforced concrete columns by circularisation and FRP confinement

Thong Minh Pham

University of Wollongong, tmp@uow.edu.au

Viet Le Doan

University of Wollongong, vld143@uowmail.edu.au

Muhammad N. Hadi

University of Wollongong, mhadi@uow.edu.au

Follow this and additional works at: https://ro.uow.edu.au/eispapers

Part of the Engineering Commons, and the Science and Technology Studies Commons

Research Online is the open access institutional repository for the University of Wollongong. For further information contact the UOW Library: research-pubs@uow.edu.au 


\title{
Strengthening square reinforced concrete columns by circularisation and FRP confinement
}

\begin{abstract}
A technique called circularisation where segmental circular concrete covers made of different concrete strengths (40 MPa, $80 \mathrm{MPa}$ and $100 \mathrm{MPa}$ ) was used to change a square column to a circular column. The applicability of the circularisation method was experimentally studied for a wide range of concrete strengths (from $40 \mathrm{MPa}$ to $100 \mathrm{MPa}$ ). The behaviour of the strengthened specimens under different loading conditions including concentric loading, eccentric loading $(25 \mathrm{~mm}$ and $50 \mathrm{~mm})$ and flexural bending is investigated. The experimental results demonstrate that using high strength concrete (HSC) for the additional covers to strengthen existing square reinforced concrete (RC) columns provides higher load-carrying capacity than covers made of normal strength concrete. The HSC covers and the concrete cores worked as a composite material to failure. The FRP strain at peak load was observed for the purpose of estimating the specimens' capacity. The distribution of FRP strain around the circumference of the column section is also reported.
\end{abstract}

\section{Keywords}

confinement, circularisation, columns, concrete, reinforced, frp, square, strengthening

\section{Disciplines}

Engineering | Science and Technology Studies

\section{Publication Details}

Pham, T. Minh., Doan, V. \& Hadi, M. N. (2013). Strengthening square reinforced concrete columns by circularisation and FRP confinement. Construction and Building Materials, 49 (2013), 490-499. 


\title{
1 Strengthening Square Reinforced Concrete Columns by Circularization and \\ 2 \\ FRP Confinement
}

3

4

5

6

$7 \quad$ Abstract

8

9

\author{
Thong M. Pham ${ }^{\mathrm{a}}$, Le V. Doan ${ }^{\mathrm{b}}$ and Muhammad N. S. Hadi ${ }^{\mathrm{b}, *}$ \\ ${ }^{\mathrm{a}}$ School of Civil, Mining and Environmental Engineering, University of Wollongong, NSW 2522, Australia. On \\ leave Faculty of Civil Engineering, HCMC University of Technology, Ho Chi Minh City, Vietnam. \\ ${ }^{\mathrm{b}}$ School of Civil, Mining and Environmental Engineering, University of Wollongong, NSW 2522, Australia.
}

\begin{abstract}
A technique called circularization where segmental circular concrete covers made of different concrete strengths (40 MPa, $80 \mathrm{MPa}$ and $100 \mathrm{MPa}$ ) was used to change a square column to a circular column. The applicability of the circularization method was experimentally studied for a wide range of concrete strengths (from $40 \mathrm{MPa}$ to $100 \mathrm{MPa}$ ). The behaviour of the strengthened specimens under different loading conditions including concentric loading, eccentric loading ( $25 \mathrm{~mm}$ and $50 \mathrm{~mm}$ ) and flexural bending is investigated.
\end{abstract} The experimental results demonstrate that using high strength concrete (HSC) for the additional covers to strengthen existing square reinforced concrete (RC) columns provides higher load-carrying capacity than covers made of normal strength concrete. The HSC covers and the concrete cores worked as a composite material to failure. The FRP strain at peak load was observed for the purpose of estimating the specimens' capacity. The distribution of FRP strain around the circumference of the column section is also reported.

Keywords: Fibre reinforced polymer; Eccentric load; Strengthening; Strain distribution; Shape modification; Square columns.

\footnotetext{
* Corresponding author. Email: mhadi@uow.edu.au
} 


\section{1 \\ 1. Introduction}

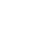

columns has been proven to increase the strength, stiffness and ductility of the strengthened

columns. Most of the existing columns are square or rectangular in cross sections, which reduce

the effectiveness of FRP confinement. Thus, it is believed that shape modification technique in which a square column is changed to a circular column before wrapping with FRP improves the confinement effect. This shape modification idea had been explored by Priestley and Seible [1].

In their approach, precast concrete bolsters were bonded to obtain a circular or elliptical section before wrapping with FRP sheets. Using fast-cured cement inside FRP straps was also utilized to modify cross sections of columns by Saadatmanesh et al. [2] while post-tensioned FRP shells were carried out as another shape modification technique by Yan and Pantelides [3]. The shear strength, flexural ductility and lap-slice performance of the retrofitted columns under seismic loads were investigated in the studies by Priestley and Seible [1] and Saadatmanesh et al. [2]. No axial load capacity was investigated in the above papers. Hadi et al. [4] proposed a new technique for strengthening an existing square column by circularizing with four precast segmental circular concrete covers and then wrapping them with FRP. The columns were tested under concentric loading, eccentric loading and flexural bending. The results indicated that this technique significantly improves the strength and ductility of the strengthened columns.

As a result, there are two ways to strengthen a square RC column by wrapping with FRP. The first common method is to round the corners of the column and then wrap it with FRP. The second method is to use the proposed method, which does not need to round the corners. So, the 
1 proposed technique reduces labour-works by not rounding the corners, which must be

2 conducted on site in real structures. On contrast, casting the segmental covers is constructed in

3 a factory which may reduce the labour cost and increase the quality control. Therefore, the

4 method proposed by Hadi et al. [4] is promising for the practical engineering.

5 Sequentially, the studies above have shown that a combination of shape modification and

6 FRP has been used to successfully strengthen existing square RC columns. Hadi et al. [4] made

7 the same concrete strength for both the column core and the precast segmental covers. This

8 study uses high strength concrete (HSC) in the covers to increase the load carrying capacity of

9 columns. However, using HSC leads to different behaviours between the concrete core and the 10 segmental concrete covers. Also, HSC was found to achieve lower effective confinement than

11 normal strength concrete [5]. Therefore, this study investigates the applicability of the proposed 12 method for existing square RC concrete columns strengthened by HSC segments and FRP. The compressive concrete strength of the column cores was $40 \mathrm{MPa}$ while the segmental covers had compressive design strength of $40 \mathrm{MPa}, 80 \mathrm{MPa}$ to $100 \mathrm{MPa}$. The capacity, ductility and failure modes of the columns were investigated. In addition, load - deflection response and strain distribution of FRP around the tested columns were also studied.

\section{Confined Concrete and Interaction Diagrams}

\subsection{Confined Concrete}

The confinement model was firstly reported based on tri-axial tests of small plain concrete cylinders. Richart et al. [6] proposed the following linear relationship between the confined concrete strength and the confining pressure: 


$$
f_{c c}^{\prime}=f_{c o}^{\prime}+k_{1} f_{l}
$$

2 where $f^{\prime}{ }_{c c}$ is the strength of confined concrete, $f^{\prime}{ }_{c o}$ is the strength of unconfined concrete, $f_{l}$ is

3 the confining pressure, and $k_{1}$ is a coefficient that is a function of lateral pressure and cross

4 sections, which was taken as 4.1. This model is based on active confinement to calculate the

5 strength of confined concrete. Richart et al. [7] also found that the confined concrete strength

6 with passive confinement pressure was same as the strength of concrete with active

7 confinement from lateral hydraulic pressure. Mander et al. [8] suggested the following

8 nonlinear relationship based on the ultimate strength surface:

$$
f_{c c}^{\prime}=f_{c o}^{\prime}\left(-1.254+2.254 \sqrt{1+\frac{7.94 f_{l}}{f_{c o}^{\prime}}}-2 \frac{f_{l}}{f_{c o}^{\prime}}\right)
$$

9 17

Mander et al. [8] proposed the above model based on the experiments of steel confined concrete. This model was adopted by ACI 440.2R-02 [9] to design externally bonded FRP systems for strengthening concrete structures. However, using this model to calculate the strength of FRP confined concrete was inappropriate [10]. As a result, several studies proposed confinement models, which exhibited a reasonable agreement with experimental results, for FRP confined concrete [11-15]. Lam and Teng's model [11] was adopted herein to calculate the 18 where is the effective confining pressure, which can be estimated by:

$$
f_{l, a}=k_{\varepsilon} \frac{2 f_{f e} t}{d}
$$


1 where and $t$ are respectively the rupture stress and the thickness of FRP, $d$ is the diameter of

2 a column, and $k_{\varepsilon}$ is the FRP strain efficiency factor which was defined by Harries and Carey [16]

3 and then taken as 0.586 by Lam and Teng [11].

$4 \quad$ Unfortunately, Lam and Teng's model [11] is applicable for concrete having unconfined

5 compressive strength less than 55 MPa while this study used concrete with compressive 6 strengths ranging between $40 \mathrm{MPa}$ and $100 \mathrm{MPa}$. A model for FRP confined HSC is necessary

7 for estimating the strength of confined concrete made of HSC. Models for FRP confined HSC

8 do not show a significant difference from models for normal strength concrete. Thus, the model

9 proposed by Lam and Teng [11] was used to calculate the confined concrete strength of all 10 tested columns.

The confinement mechanism of the tested columns is very complicated when NSC is used in column cores and HSC in the segmental covers. This combination may cause different confinement efficiency [5]. The concrete of the column cores and the segmental covers has differences in the axial concrete stiffness and the axial strain at peak load. These differences lead to inconsistency in transferring the applied load to the core and the covers. The different behaviours of the tested columns are investigated experimentally and the nominal confined concrete strength was calculated as follows:

$$
f_{c c}^{\prime}=\frac{f_{c c 1}^{\prime} A_{1}+f_{c c 2}^{\prime} A_{2}}{A_{1}+A_{2}}
$$

where $f^{\prime}{ }_{c c 1}$ and $f^{\prime}{ }_{c c 2}$ are respectively the confined concrete strength of the column core and the segmental covers, and $A_{1}$ and $A_{2}$ are the cross sectional area of the column core and the total cross sectional area of the segmental covers. 


\subsection{Interaction diagrams}

ACI-440.2R [17] suggested that interaction diagrams for FRP confined concrete columns could be established using simple sectional analysis procedures developed for RC concrete columns. Such diagrams must satisfy strain compatibility and force equilibrium. The only difference for establishing interaction diagrams for FRP confined concrete columns is the use of a FRP confined concrete stress-strain curve instead of the stress-strain curve for unconfined concrete. Two methods were adopted to analyse the interaction diagrams as suggested by Hadi et al. [4]. However, this study only reports the "equivalent method", which provides a closer estimation with the experiments, to verify the experimental results.

A theoretical axial load - bending moment interaction diagram includes four points: (a) the pure axial condition; (b) the condition where the strain at the extreme compression fibre is equal to the ultimate confined concrete strain and the strain at the extreme tension fibre is zero; (c) the balanced condition where the strain at the extreme compression fibre is equal to the ultimate confined concrete strain and the steel bar nearest to the tensile face has just yielded in tension; and (d) the pure flexural condition.

The axial load $(P)$ proposed by ACI-440.2R [17] was calculated as follows:

$$
P=0.85 f_{c c}^{\prime}\left(A_{g}-A_{s}\right)+f_{y} A_{s}
$$

where $A_{g}$ and $A_{s}$ are respectively the cross sectional area of the column and the longitudinal reinforcement, and $f_{y}$ is the yield stress of the longitudinal reinforcement. 
2 Whitney stress block assumptions to make the force equilibrium in the FRP confined concrete

3 columns. The Whitney stress block was used to transfer non-uniform compressive confined

4 concrete stresses to rectangular distribution of stresses in accordance with AS 3600 [18].

\section{3. Experimental Program}

$6 \quad 3.1$. Design of Specimens

Sixteen identical square RC specimens were cast to have a cross-section with $150 \mathrm{~mm}$ in

8 sides and $800 \mathrm{~mm}$ in height. All specimens had identical internal steel reinforcement and were 9 designed according to AS 3600 [18]. Each specimen was reinforced with four N12 (12 mm 


\subsection{Test Configuration}

All tests were carried out at the laboratories of the School of Civil, Mining and Environmental Engineering, University of Wollongong. The specimens were subdivided into four groups. The first group (Group R) was set as a reference group with no further modification and strengthening. The columns of the other three groups were bonded with four segmental circular concrete covers to modify the cross section from square to circle. The concrete strength of the additional segments of these groups was unique for each other. Based on the strength (in MPa) of the additional segments, these groups were named as Groups C40, C80 and C100 indicating covers have design compressive strengths of 40, 80 and $100 \mathrm{MPa}$, respectively. It is noticed that the compressive concrete strengths reported in Table 1 are the actual values. The modified columns were then wrapped with three CFRP layers.

From each group, the first specimen was subjected to an axial concentric load and the next two specimens were tested with $25 \mathrm{~mm}$ or $50 \mathrm{~mm}$ eccentric loading. The last specimen was tested under a four-point loading regime. The specimens were labelled based on the compressive strength of the covers followed by the loading condition. For examples, Specimen C80-50 had an $80 \mathrm{MPa}$ compressive strength of the covers and was tested under $50 \mathrm{~mm}$ eccentricity. Table 1 shows the test matrix used in this study and the details of the specimens are shown in Fig. 1.

\subsection{Specimen Fabrication}

Two plywood formworks were used to construct the column cores and the segmental circular concrete covers. For the segmental circular concrete covers, a box of 34 rectangular 
1 segments having a dimension of $51 \times 170 \mathrm{~mm}^{2}$ was built. A section mould of foam was added to

2 each rectangular segment in order to create a mould for the concrete covers. Each segmental

3 circular concrete cover had a chord of $150 \mathrm{~mm}$ (equal to the side length of the column core) and

4 the height of the segment was $31 \mathrm{~mm}$.

\section{$5 \quad$ 3.3.1. Circularisation Process}

The segmental circular concrete covers were taken out of the formwork after 28 days. The foams on the covers were first removed and the surface of the segments was ground and cleaned to be smooth. Before bonding the segments, the column surface was cleaned and any dust was removed. The adhesive was a mix of epoxy resin, slow hardener and silica microsphere with a ratio of 5:1:10. The adhesive was evenly spread onto the segment surface, which were then bonded onto the column surface. The epoxy resin had 54 MPa tensile strength, 2.8 GPa tensile modulus, and 3.4\% tensile elongation [19].

Four segmental circular concrete covers were bonded on the surface of a column to modify the shape of the cross section from square to circle. After the segments were bonded, adjustable steel straps were used to hold them. The modified specimens were then left to dry for three days before they were externally confined. Fig. 2 illustrates details of the circularisation process. In practice, the surface of the column cores and the segments may not fit together because of construction errors. As a result, any effort of bonding the segments to the column core causes cracking of the segments. Fiber reinforced segments should be used in such cases to provide ductile structural elements. 


\subsubsection{Construction of External Confinement}

Wet-layup method was used to wrap the specimens with CFRP using epoxy resin. The specimens were confined with separate CFRP rings. Firstly, epoxy resin was spread onto the specimen surface and the first CFRP layer was attached. Next, epoxy resin was spread again on the surface of the first CFRP layer and the second layer was attached. The same procedure was followed until three CFRP layers were bonded with a notice that $100 \mathrm{~mm}$ overlap was maintained at the third layer. An additional layer of CFRP was wrapped at both ends of the specimens to prevent premature damage at the ends. The specimens were then left to dry for three days as specified by the supplier.

\subsection{Preliminary Tests}

The compressive concrete strength was recorded at 28 days, 56 days and at the testing time. Since the specimens were tested at different ages, three cylinders were tested on the same day of testing the specimen to determine the compressive concrete strength at that time. Table 1 summarizes the average compressive concrete strength of the tested columns during testing time. To determine the mechanical properties of CFRP, CFRP flat coupon tests were conducted according to ASTM D7565 [20]. The average width of the coupons was $25.6 \mathrm{~mm}$ and the average maximum tensile force per unit width was $2089 \mathrm{~N} / \mathrm{mm}$. The strain at the average maximum tensile force and the average elastic modulus were $0.0174 \mathrm{~mm} / \mathrm{mm}$ and $121 \mathrm{kN} / \mathrm{mm}$, respectively. The average tensile strength of N12 and R6 was respectively $568 \mathrm{MPa}$ and 478 MPa. 


\subsection{Instrumentation and Test Procedure}

Strain gauges were horizontally attached onto the CFRP surface to investigate the actual strain of CFRP at the critical locations around the circumference of the column sections. Four strain gauges were symmetrically bonded in all concentrically loaded columns while each beam specimen had two strain gauges, one at the compression and one at the tension regions. Meanwhile, each eccentrically loaded column had ten strain gauges which were used to observe the strain distribution at the middle CFRP ring. Because of the significance of the FRP strain in the compression region, more strain gauges were concentrated in this region. The strain gauges were then connected to a data logger and a control computer. Details of the positions of strain gauges are shown in Fig. 3.

A specific loading system was used to conduct eccentric loading tests. Detailed description of the loading system could be found in Hadi and Widiarsa [21]. For flexural tests, two four-point loading frames were used. The "square" four-point loading frame introduced by Hadi and Widiarsa [21] was used for Specimen R-F while the "circular" four-point loading frame used by Yazici and Hadi [22] was used for Specimens C40-F, C80-F and C100-F.

Axial deflection of the columns was monitored by a Linear Variable Differential Transformer (LVDT) attached to the lower moving plate of the compression machine. In order to measure the lateral deflection of the eccentrically loaded columns and midspan deflection of the flexural tests, a laser triangulation sensor was used and connected to the data logger as well. For the column tests, the laser triangulation sensor was set up at mid-height of the columns. For the beam tests, the laser triangulation sensor was placed on a hole located at midspan of the 
1 bottom loading plate. The Denison $5000 \mathrm{kN}$ testing machine was used for testing all of the

2 specimens. The tests were conducted as deflection controlled with a rate of $0.3 \mathrm{~mm} / \mathrm{min}$. All

3 columns were capped at both ends by using high strength plaster to ensure even distribution of

4 forces. Calibration was carried out to ensure the specimens were placed at the centre of the 5 machine.

6 Experimental e lt an i ion

7

\subsection{Failure Modes}

All Specimens were tested to failure. The load and displacement data were collected using the data logger connected to the compression machine.

For concentrically loaded columns, Column R-0 failed by dedonding of concrete cover and buckling of the longitudinal steels at midheight of the columns. Three confined columns failed in a brittle manner with rupture of FRP and crushing of the concrete covers. FRP ruptured at midheight of the columns with a loud sound. The concrete cover including the segmental circular concrete covers and the concrete cover of the original columns crushed while the concrete core inside the longitudinal steels was still confined as shown in Fig. 4. The columns made of higher concrete strength were observed to fail rather suddenly than the others.

For eccentrically loaded columns, tension cracks in concrete occurred between two FRP rings located at midheight of the columns were found at early stage of the loading. FRP confined concrete columns under eccentric loading failed by FRP rupture followed by concrete crushed at the compression side. The rupture of FRP was always observed at midheight. In this 
1 study, half of the tested columns had two types of concrete having different strengths. These

2 differences may lead to debonding at the interface between the two types of concrete. Thus, the

3 tested columns were unwrapped to observe the connection between the additional segments and

4 the column core. As expected, the bonding between the additional segments and the column

5 core was good for all columns. Fig. 4 shows Specimen C80-25 after being tested and FRP

6 peeled off.

7

8

Specimens under flexural tests failed by the fracture of longitudinal steels in the tension side and crushing of the concrete in the compression side. No FRP rupture was observed in the tests. For Specimen R-F, two types of cracks were observed. Vertical cracks occurred first due to flexural stresses. These cracks started at mid-span and bottom of the beam and then new cracks moved to near the ends of the beam. These cracks rapidly opened when the applied load was reaching the peak load. The inclined cracks near the ends of the beams were observed later due to shear effect. For Specimens C40-F, C80-F and C100-F, the same cracking pattern was observed after unwrapping the tested beams as shown in Fig. 5. Additionally, arch action was found and detailed below in the following sections.

\subsection{Load - Deflection Responses}

The first column of each group was tested under concentric loading. Fig. 6 shows axial load versus axial deflection of the columns. The axial load of Specimen R-0 increased to the peak load at which the longitudinal steel yielded, and then the load decreased to failure. The shape of the axial load - deflection diagrams of the confined columns shown in Fig. 6 is identical to each other, which is a bi-linear increase. The first portion of the diagrams quickly 
1 increased to the yield load before gradually increasing to the peak load. Then, the specimens

2 suddenly failed by a very loud sound caused by FRP rupture. Fig. 6 also shows that slopes of the

3 tested columns (specimen stiffness) are approximately identical in each corresponding stage.

4 The similarity in slope shows that effects of the additional segment strength on the specimen

5 stiffness could be negligible. In addition, the higher concrete strength of the segmental covers,

6 the higher yield load and peak load were obtained. As compared to Specimen R-0, the increase

7 of the peak load of Specimens C40-0, C80-0 and C100-0 was respectively 261\%, 268\%, and

$8286 \%$. The increase of yield load of $16 \%$ and $15 \%$ was achieved for Specimens C80-0 and

9 C100-0 compared to Specimen C40-0, respectively. It is commonly assumed that the confinement effect caused by FRP is negligible at yield load. Thus, the increase of the yield load of Specimens C80-0 and C100-0 proved that the contribution of the high strength concrete of the segments. Meanwhile, the increase of the peak load of Specimens C80-0 and C100-0 was respectively $2 \%$ and $7 \%$ compared to Specimen C40-0. The increase of the axial load at the peak load being smaller than at the yield load confirmed that FRP confinement on HSC is less efficient than normal strength concrete.

The axial load - deflection diagrams of the columns under eccentric loads are plotted in Figs. 7-8. The shape of the load - deflection diagrams of the eccentrically loaded columns was different from those of the columns under concentric load. The load - deflection diagrams of the confined columns under $25 \mathrm{~mm}$ eccentric load steadily increased to the peak load, and then sustained a load before failing by rupturing FRP at the compression side. The increase of the peak load of Specimens C40-25, C80-25 and C100-25 compared to Specimen R-25 was 129\%, $155 \%$ and $162 \%$, respectively. As shown in Fig. 7, the increase of the axial deflection and 
1 lateral deflection is quite similar before reaching the peak load. The lateral deflection then

2 increased much faster than the axial deflection as the axial load was sustained.

4 shown in Fig. 8. The increase of the peak load of Specimens C40-50, C80-50 and C100-50

5 compared to Specimen R-50 was 139\%, 178\% and 175\%, respectively. It is confirmed that the

6 efficiency of FRP confined concrete decreases when eccentricity was introduced. Additionally,

7 the axial load of Specimens C80-50 and C100-50 fluctuated after the peak load, which resulted

8 from redistribution and rearrangement of the micro structures inside the columns. This

9 phenomenon did not occur in Specimen C40-50 having the same concrete strength between the 10 column core and the segmental circular concrete covers. In terms of deflection, unlike the 11 specimens tested under $25 \mathrm{~mm}$ eccentric load, the increase of the lateral deflection of specimens under $50 \mathrm{~mm}$ eccentricity was higher than that of the corresponding axial deflection at all stages.

Fig. 9 shows the load - midspan deflection diagrams of the tested beams under flexure. The beams wrapped with FRP exhibit a large increase in their load-carrying capacity compared to the reference beam. The load - midspan deflection diagrams of the beams confined with FRP exhibit an ascending branch after yielding.

\subsection{Strain Distribution of FRP}

FRP rupture was observed at two potential locations: the extreme compression fibre for the eccentrically loaded columns, and the positions close to the corners of the column core and out of the overlap region for the concentrically loaded columns. 
For columns under concentric loads, the FRP strain at the yield load was approximately 0.0014, which was an average reading of the strain gauges out of the overlap zone, while the FRP strain at the peak load was 0.012 . Those strains confirmed an assumption that FRP effect at the yield load could be negligible as the FRP strain at that stage was $8 \%$ of the ultimate strain of

FRP from flat coupon tests. The FRP strain efficiency factor, defined as the ratio of the actual rupture strain and the ultimate strain of FRP from flat coupon tests, of the tested columns was

0.7. The axial load - FRP strain diagrams of the concentrically loaded columns are plotted in Fig. 10. The FRP of the concentrically loaded columns always ruptured at the peak load.

Conversely, the FRP of eccentrically loaded columns did not rupture at the peak load. Fig. 11 shows the axial load - FRP strain diagrams at the extreme compression region, which is Position 1 (S1) in Fig. 3b. The peak load occurred at very early stage as observed in Specimen C100-50, where the FRP strain was 0.0014 at the peak load and 0.0116 at the ultimate load. Otherwise, the FRP strain of Specimen C100-25 was 0.0098 at the peak load and 0.0144 at the ultimate load. As shown in Fig. 11, the FRP strain at the peak loads varied from 12\% to 68\% of the FRP strain at rupture. In this study, the FRP strain efficiency factor of specimens under eccentric load was 0.72 , in which the actual rupture strain of FRP was the strain reading at Position 1 (S1) as shown in Fig. 3b.

Fig. 12 shows the distribution of FRP strain around the circumference of Column C80-25. The FRP strain of Column C80-25 illustrates a pattern of strain distribution for eccentrically loaded columns. The FRP strain was the highest at Position 1 (S1) and then regularly declined till Position 6 (S6). It is believed that no confinement effect resulted from FRP is available at the 
1 tension region in a column. Interestingly, the FRP strain was not negligible at Location 6 as

2 shown on the "ultimate load" line in Fig. 12. Thus, the FRP strain at Position 6 could not result

3 from confinement effect, but caused by stretching the FRP from the compression region in the

4 column section.

5 4.4. Ductility

Ductility of the tested specimens was calculated as the ratio of the deflection at $85 \%$

7 post-peak load $\left(\delta_{u}\right)$ and the yield load $\left(\delta_{y}\right)$ as described in Eq. 7 and summarised in Tables 2-3.

$$
\lambda=\frac{\delta_{u}}{\delta_{y}}
$$

8

9

The deflection at $85 \%$ post-peak load was determined by the deflection corresponding to the axial load dropping to $85 \%$ of the peak load. The definition of the yield load was adopted from Pessiki and Pieroni [23], which was obtained as follows. A best-fit line to the linear portion of the load - deflection diagram for each specimen was implemented. This line was then extrapolated to intersect with the maximum load sustained by the column. The load corresponding to this intersection is the yield load. In addition, the axial load - deflection graphs of the concentrically loaded columns had the ascending branch after yielding. Thus this approach was inappropriate in these cases. Determining the yield loads of such specimens was modified. Two best-fit lines for the two linear portions of the diagrams were made, and then the yield load was determined by an intersection of the two above lines.

Tables 2 - 3 show that the confined columns exhibited higher ductility relative to the reference columns. The concrete strength of Groups C80 and C100 was designed to have 
1 different strengths. However, the concrete strength of these groups was quite similar, thus their

2 behaviours were very similar. The ductility of the columns tested by the same condition of

3 Groups C40, C80 and C100 was quite similar. This behaviour demonstrates that the influence

4 of the concrete strength of the segments on ductility of FRP confined columns is negligible.

\section{4.5. Interaction Diagram}

The experimental interaction diagrams in this study were drawn based on four points: (1) a pure axial load of the columns under concentric loads, (2) two points of eccentric loads of 25 $\mathrm{mm}$ and $50 \mathrm{~mm}$, where the axial loads were recorded from the testing machine and the bending moments were calculated by Eq. 8, and (3) a pure bending moment observed from the four-point loading tests. The experimental interaction diagrams are shown in Fig. 13.

$$
\mathrm{M}=\mathrm{P}_{\max }(\mathrm{e}+\delta)
$$

where $P_{\max }$ is the peak axial load, $e$ is the original eccentricity, and $\delta$ is the lateral deflection at the peak load.

The theoretical interaction diagrams were established to describe the axial load and bending moment capacity of the tested columns. The actual rupture strain of FRP on the tested columns was different than the value suggested by ACI-440.2R (2008). As mentioned above, the columns under eccentric loads reached the peak load as the FRP strain was much lower than the rupture strain observed at the ultimate load. In this study, the FRP strain was set as 0.7 for concentrically loaded columns and 0.34 for columns under eccentric loads. Fig. 14 shows the experimental - theoretical interaction diagrams of the tested columns. 
Fig. 14 demonstrates that using the proposed procedure to calculate the interaction

2 diagrams provides good agreement with the experimental results. The differences between the

3 theoretical and experimental results were $7.25 \%$ and 3.05\% for concentrically and eccentrically

4 loaded columns, respectively. In order words, the estimation of the bending moment did not

5 show good agreement with the experimental results because of the following reasons.

6

7

8

Specimen R-F failed with flexural behaviour evidenced by vertical cracks. Thus, the experimental bending moment of this beam is close to the calculation as shown in Fig. 14 . Meanwhile, the specimens wrapped with FRP under flexural tests failed in a manner of a combination of flexure and shear as shown in Fig. 5 showing the vertical and inclined cracks. The inclined cracks were resulted from the arch action which resulted in the increase of the beam capacity. The availability of the arch action was confirmed by the FRP strain. When the vertical cracks, which were signs of flexural behaviour, occurred and opened quite large, the FRP strain was still negligible at the compression region. However, when the vertical cracks stopped developing, the FRP strain increased quickly to the value of 0.006 at such zone. To maintain equilibrium, it is assumed that a strut resulted from the arch action carried the increased load.

\section{on 1 ion}

The proposed strengthening technique was used to modify a square section to a circular section before wrapping with FRP. This technique could be utilized to improve significantly the capacity of a square column. Two concrete components including the original concrete core and the additional concrete covers worked as a composite material to failure under pure axial load, 
1 flexure, and eccentric loads. The bonding of two components observed after testing was perfect

2 bond. Thus, it is concluded that the proposed technique is able to improve the capacity of a

3 noncircular column.

4 The ductility of the strengthened columns significantly increased compared to the

5 reference columns since FRP has the same full confinement effect on the tested columns as on a

6 conventional original circular column.

7

This study also verified the application of the proposed technique for a variety of concrete strength up to $100 \mathrm{MPa}$. The experiments demonstrated that this technique could be used not only for normal strength concrete but for high strength concrete. Bonding high strength concrete covers to the column core with low concrete strength was successfully verified.

The FRP strain was recorded during the loading process. The rupture strain of FRP on the concentrically loaded columns was around 0.7 of the ultimate strain from flat coupon tests. The FRP strain at the peak load of the eccentrically loaded columns was much smaller than the rupture strain at the ultimate load. The measured FRP strain at the peak load was approximately 0.34 of the ultimate strain from flat coupon tests. This value should be used to estimate the capacity of a FRP confined concrete column under eccentric loads. In addition, distribution of FRP strain around the tested columns was also investigated. The distribution describes a decrease of FRP strain from the extreme compression fibre to the tension side of a column.

Finally, the proposed method proved to be effective in increasing the load-carrying capacity of FRP confined square column with normal strength concrete by Hadi et al. [4]. This 
1 study verifies this method with HSC and proposes the actual FRP strain to calculate the

2 capacity of FRP confined columns under both concentric and eccentric loads.

\section{3 no le gement}

4 The authors would like to acknowledge the technical assistance of Messrs Alan Grant,

5 Fernando Escribano, Cameron Neilson, Ritchie McLean and Colin Devenish. The authors also

6 thank Mr. Eric Lume for his advice on casting HSC. Furthermore, the first author would like to

7 thank the Vietnamese Government and the University of Wollongong for the support of his full

$8 \mathrm{PhD}$ scholarship. The second author would also like to acknowledge the scholarship of the

$9 \quad$ University of Da Nang and the University of Wollongong. 


\section{References}

[1] Priestley MJN, Seible F. Design of seismic retrofit measures for concrete and masonry structures. Constr Build Mater 1995;9(6):365-377.

[2] Saadatmanesh $\mathrm{H}$, Ehsani MR, Jin L. Seismic retrofitting of rectangular bridge columns with composite straps. Earthq Spectra 1997;13(2):281-304.

[3] Yan ZH, Pantelides CP. Fiber-reinforced polymer jacketed and shape-modified compression members: II - Model. ACI Struct J 2006;103(6):894-903.

[4] Hadi MNS , Pham TM, Lei X (2012) A New Method of Strengthening Reinforced Concrete Square Columns by Circularizing and Wrapping with FRP or Steel Straps. J Compos Constr, DOI: 10.1061/(ASCE)CC.1943-5614.0000335.

[5] Eid R , Roy N, Paultre P. Normal- and High-Strength Concrete Circular Elements Wrapped with FRP Composites. J Compos Constr 2009;13(2):113-124.

[6] Richart FE , Brandtzaeg A, Brown RL. A study of the failure of concrete under combined compressive stress. Bulletin 1985, Univ. of Illinois Engineering Experimental Station, Champaign, III 1928.

[7] Richart FE , Brandtzaeg A, Brown RL. The failure of plain and spirally reinforced concrete in compression. Bulletin 1990, Univ. of Illinois Engineering Experimental Station, Champaign, III 1929.

[8] Mander JB , Park R, Priestley MJN. Theoretical Stress-Strain Model for Confined Concrete. J Struct Eng 1988;114(8):1804-1826.

[9] American Concrete Institute (ACI). Guide for the design and construction of externally bonded FRP systems for strengthening concrete structures. 440.2R-02 2002, Farmington Hills, MI.

[10] Mirmiran A, Shahawy R. Behavior of concrete columns confined by fiber composites. J Struct Eng 1997;123(5):583-590.

[11] Lam L, Teng JG. Design-oriented stress-strain model for FRP-confined concrete. Constr Build Mater 2003;17(6-7):471-489.

[12] Toutanji HA. Stress-strain characteristics of concrete columns externally confined with advanced fiber composite sheets. ACI Mater J 1999;96(3):397-404.

[13] Yazici V, Hadi MNS. Normalized Confinement Stiffness Approach for Modeling FRP-Confined Concrete. J Compos Constr 2012;16(5):520-528.

[14] Pham TM, Hadi MNS. Strain Estimation of CFRP Confined Concrete Columns Using Energy Approach. J Compos Constr 2013; doi: 
[15] Pham TM, Hadi MNS. Stress Prediction Model for FRP Confined Rectangular Concrete Columns with Rounded Corners. J Compos Constr 2013; doi:10.1061/(ASCE)CC.1943-5614.0000407.

[16] Harries KA, Carey SA. Shape and "gap" effects on the behavior of variably confined concrete. Cement and Concrete Res 2003;33(6):881-890.

[17] American Concrete Institute (ACI). Guide for the Design and Construction of Externally Bonded FRP Systems for Strengthening Concrete Structures. 440.2R-08 2008, Farmington Hills, MI.

[18] Australian Standard (AS). Concrete structures. 3600:2009 2009, Sydney, NSW, Australia.

[19] WEST SYSTEM n.d. Epoxy resins and hardeners - Physical properties. 2012

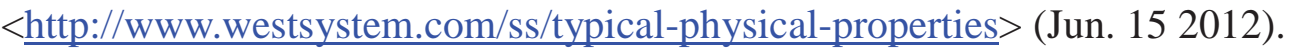

[20] ASTM. Standard test method for tensile properties of fiber reinforced polymer matrix composites used for strengthening of civil structures. D7565:2010 2010, West Conshohocken, PA.

[21] Hadi MNS, Widiarsa IBR. Axial and Flexural Performance of Square RC Columns Wrapped with CFRP under Eccentric Loading. J Compos Constr 2012;16(6):640-649.

[22] Yazici V, Hadi MNS. Axial Load-Bending Moment Diagrams of Carbon FRP Wrapped Hollow Core Reinforced Concrete Columns. J Compos Constr 2009;13(4):262-268.

[23] Pessiki S, Pieroni A. Axial load behavior of large-scale spirally-reinforced high-strength concrete columns. ACI Struct J 1997;94(3):304-314. 


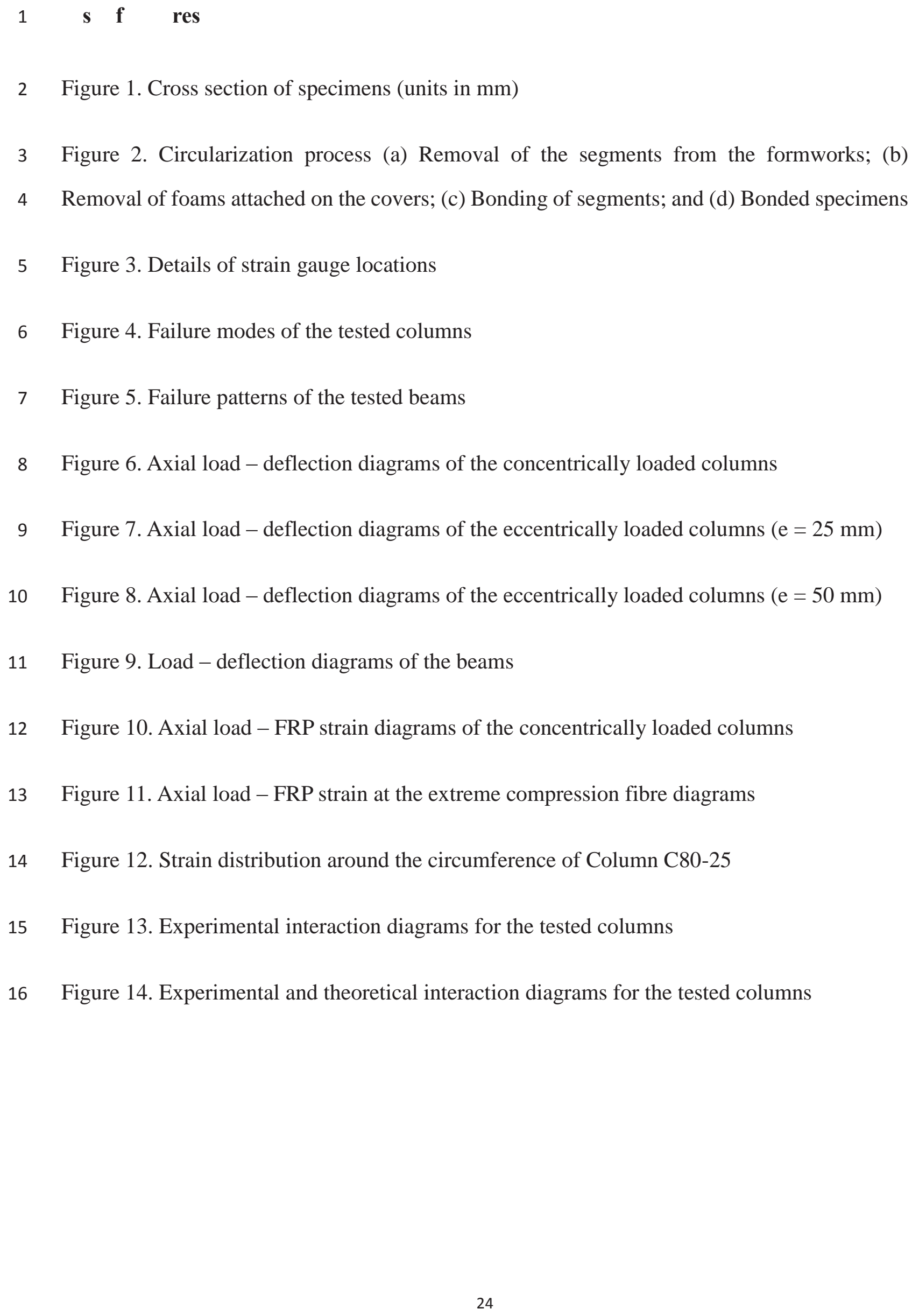




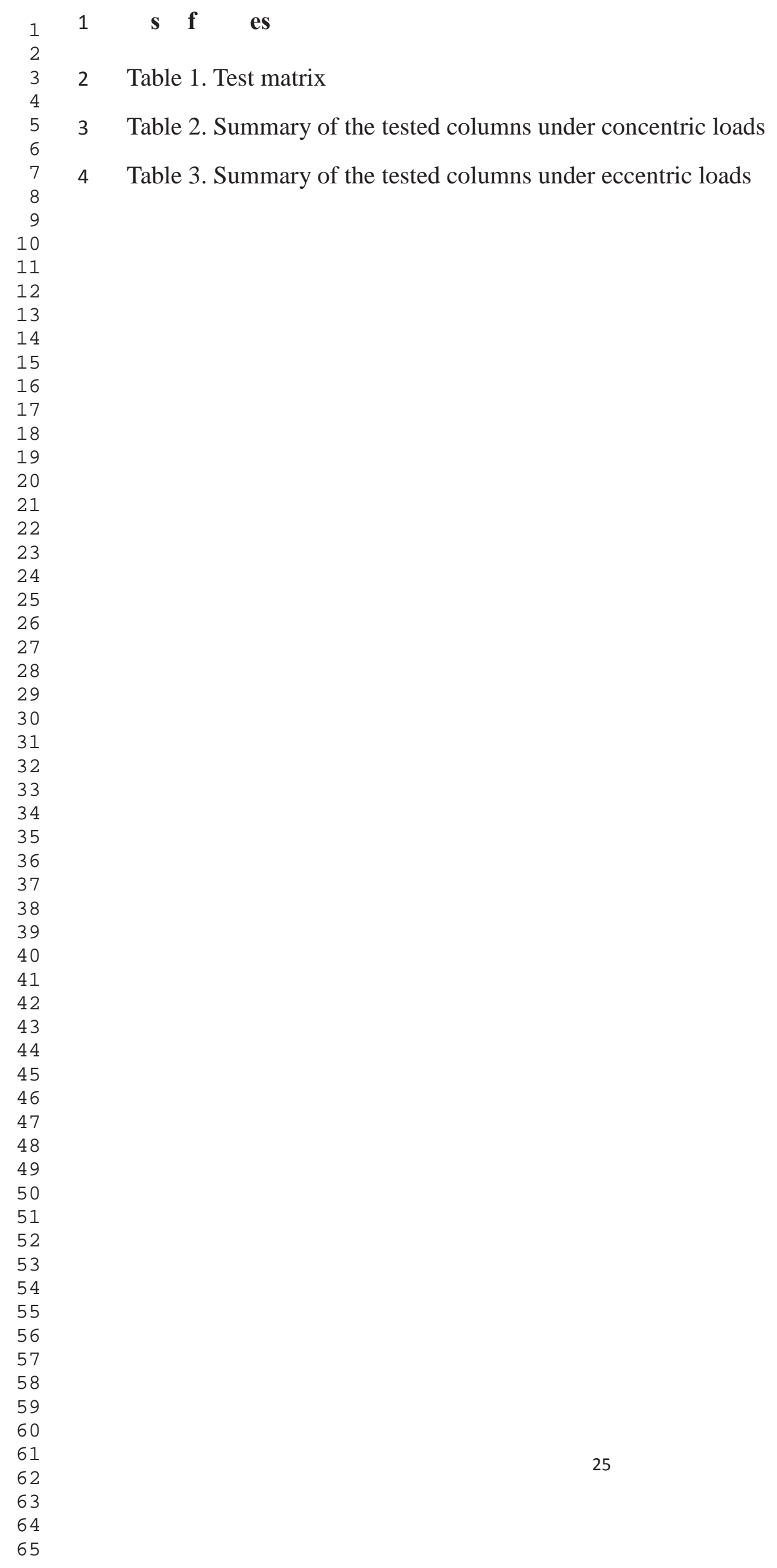


1 Table 1. Test matrix

\begin{tabular}{|c|c|c|c|c|}
\hline Specimen & $\begin{array}{l}\text { Concrete Core Strength } \\
\text { at test time (MPa) }\end{array}$ & $\begin{array}{l}\text { Concrete Cover Strength } \\
\text { at test time (MPa) }\end{array}$ & $\begin{array}{l}\text { External } \\
\text { Confinement }\end{array}$ & $\begin{array}{l}\text { Test } \\
\text { Eccentricity }\end{array}$ \\
\hline $\mathrm{R}-0$ & 44 & - & - & 0 \\
\hline $\mathrm{R}-25$ & 44 & - & - & 25 \\
\hline $\mathrm{R}-50$ & 44 & - & - & 50 \\
\hline $\mathrm{R}-\mathrm{F}$ & 44 & - & - & Flexural \\
\hline C40-0 & 58 & 58 & 3 CFRP layers & 0 \\
\hline C40-25 & 58 & 58 & 3 CFRP layers & 25 \\
\hline C40-50 & 58 & 58 & 3 CFRP layers & 50 \\
\hline C40-F & 58 & 58 & 3 CFRP layers & Flexural \\
\hline C80-0 & 59 & 98 & 3 CFRP layers & 0 \\
\hline C80-25 & 59 & 98 & 3 CFRP layers & 25 \\
\hline C80-50 & 59 & 98 & 3 CFRP layers & 50 \\
\hline C80-F & 59 & 98 & 3 CFRP layers & Flexural \\
\hline C100-0 & 63 & 101 & 3 CFRP layers & 0 \\
\hline C100-25 & 63 & 101 & 3 CFRP layers & 25 \\
\hline C100-50 & 63 & 101 & 3 CFRP layers & 50 \\
\hline C100-F & 63 & 101 & 3 CFRP layers & Flexural \\
\hline
\end{tabular}




\begin{tabular}{lllll}
1 & \multicolumn{4}{l}{ Table 2. Summary of the tested columns under concentric loads } \\
\cline { 2 - 5 } & R-0 & C40-0 & C80-0 & C100-0 \\
\hline Specimens & 892 & 2109 & 2452 & 2418 \\
\hline Yield load (kN) & 3.88 & 2.57 & 3.39 & 3.85 \\
Corres. Axial Def. (mm) & & & & \\
Ultimate load (kN) & 942 & 3400 & 3462 & 3634 \\
Corres. Axial Def. (mm) & 4.75 & 13.75 & 12 & 17.99 \\
Ductility & 1.48 & 5.45 & 4.05 & 5.03 \\
\hline
\end{tabular}

18

19

20

21

22

23

24

25

26

27

28

29

30

31

32

33

34

35

36

37

38

39

40

41

42

43

44

45

46

47

48

49

50

51

52

53

54

55

56

57

58

59

60

61

62 
1 Table 3. Summary of the tested columns under eccentric loads

Specimens

Yield load $(\mathrm{kN})$

Corres. Axial Def. (mm)

Ultimate load $(\mathrm{kN})$

Corres. Axial Def. (mm)

Corres. Lateral Def. (mm)
$\mathrm{R}-25 \quad \mathrm{C} 40-25 \quad \mathrm{C} 80-25$

C100-25

$\mathrm{R}-50$

C40-50 C80-50 C100-50

$\begin{array}{llllllll}600 & 1423 & 1558 & 1585 & 423 & 887 & 1029 & 1069\end{array}$

$2.47 \quad 3.47$

2.57

2.79

3.38

$3.07 \quad 2.35$

2.3

$\begin{array}{llllllll}633 & 1513 & 1762 & 1741 & 423 & 969 & 1080 & 1107\end{array}$
Ductility

5.52

4.79

3.38

4.05

3.57

2.54

\section{2}



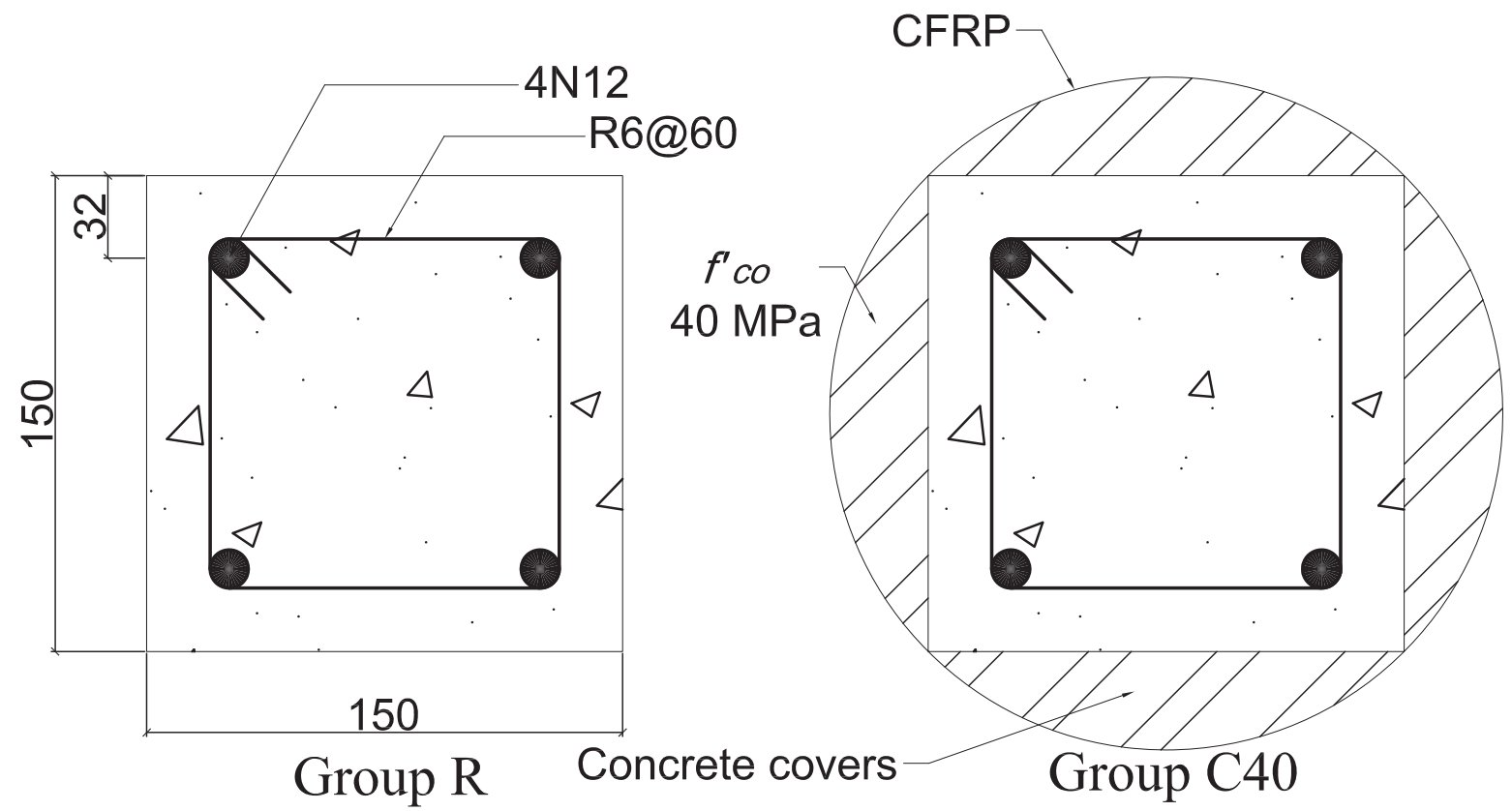

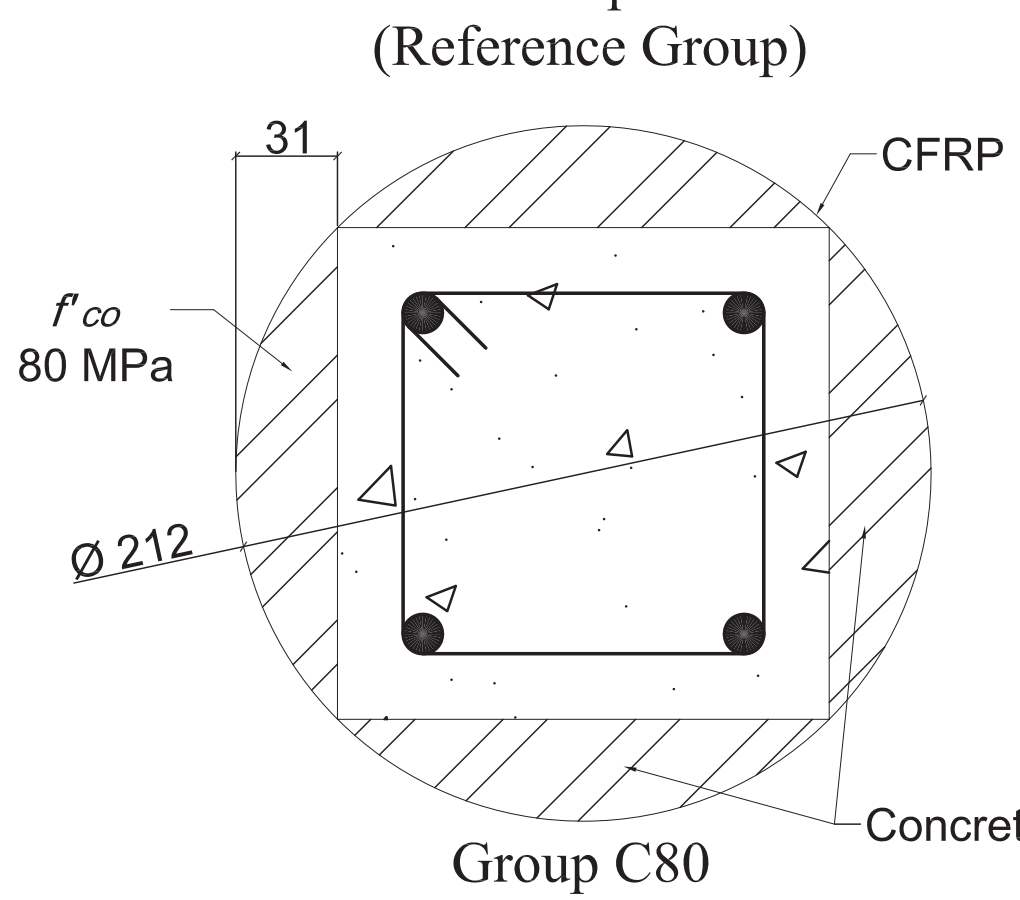

(Circularization + CFRP)
(Circularization + CFRP)

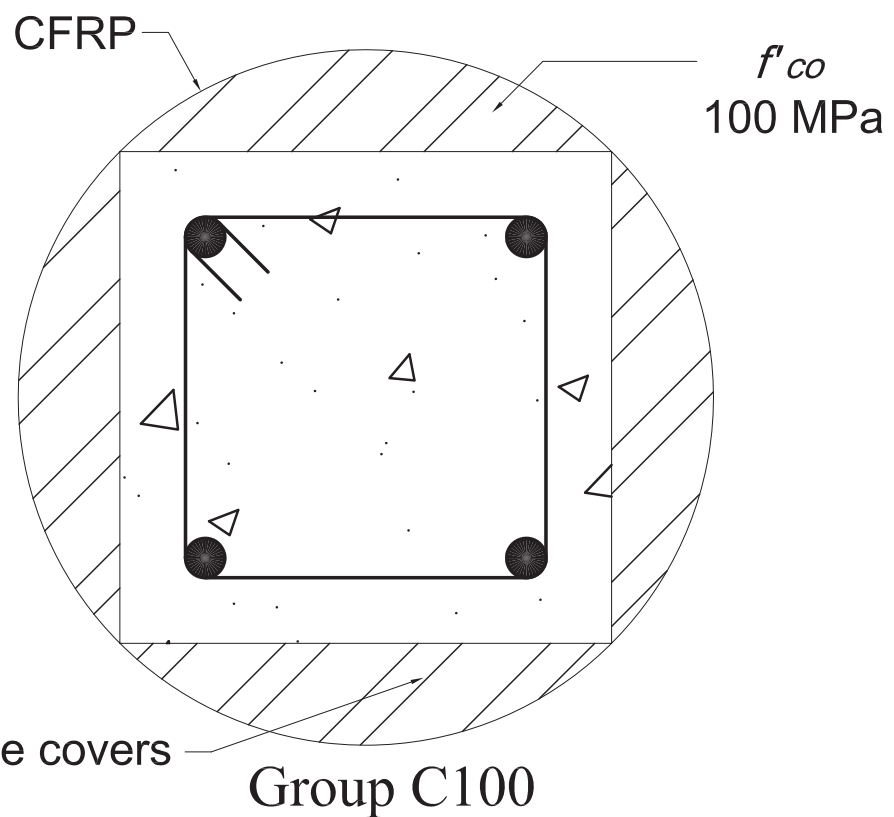

(Circularization + CFRP) 


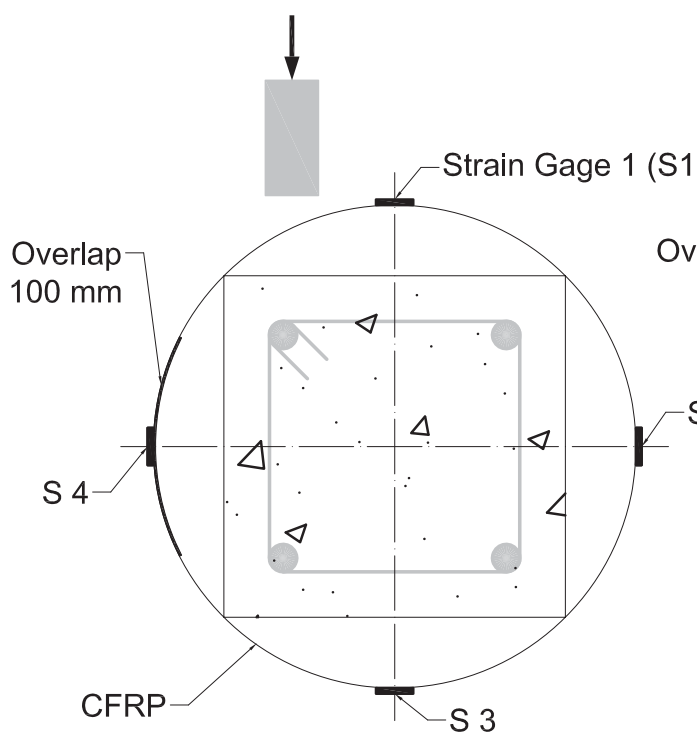

(a) Concentrically Loaded Column

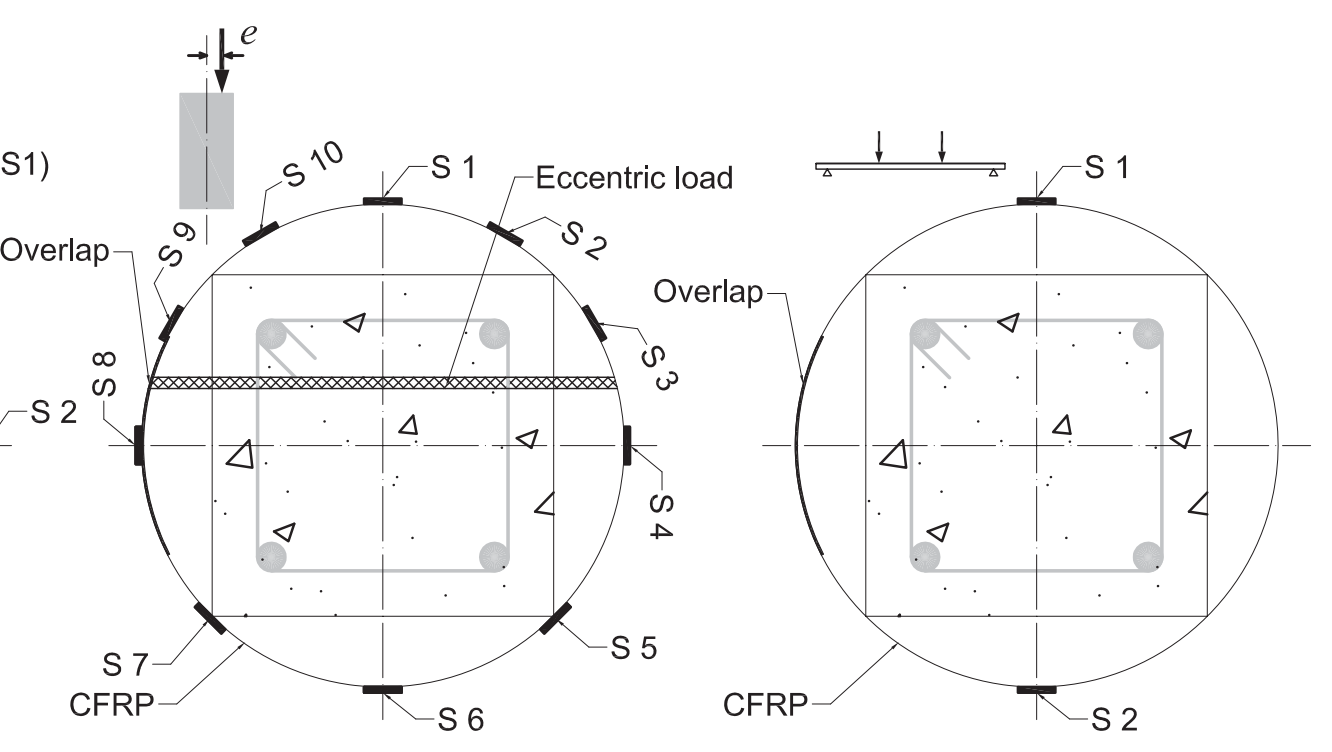

(c) Beam specimen

(b) Eccentrically Loaded Column 


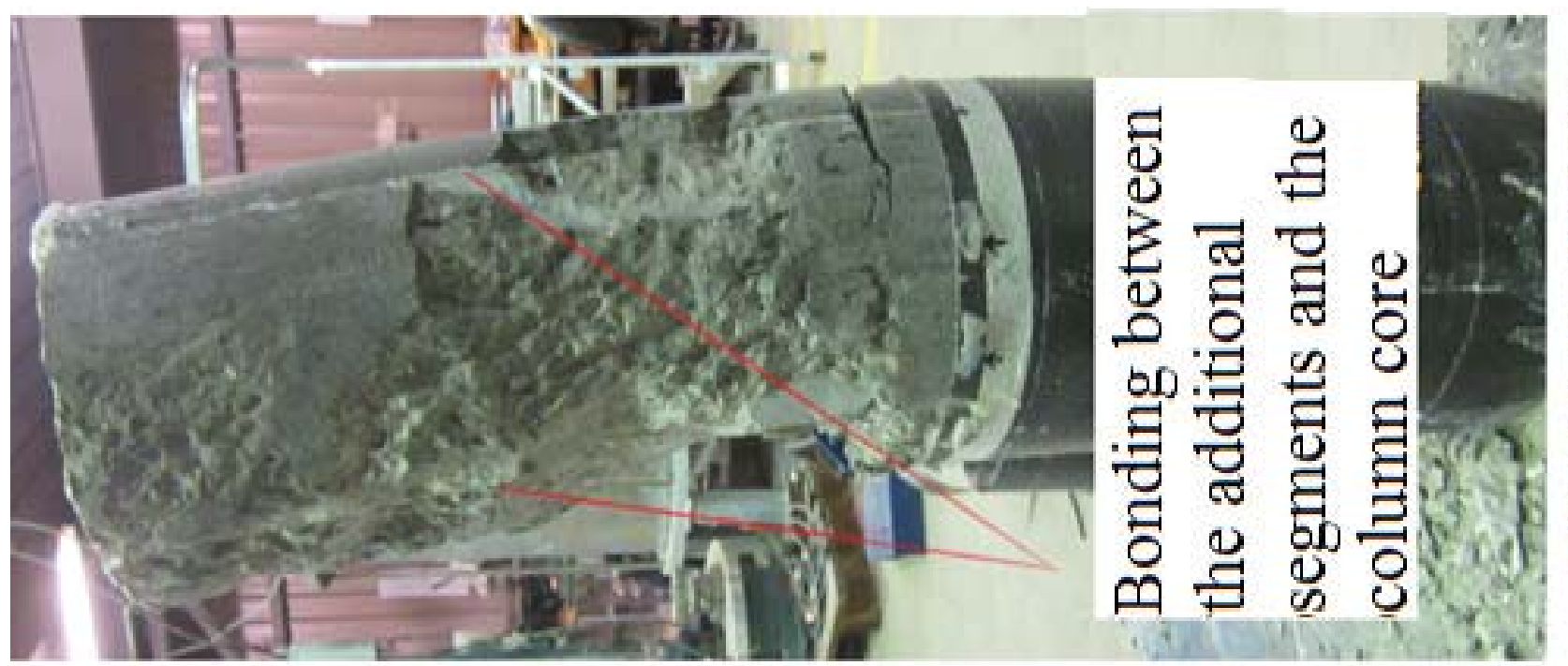

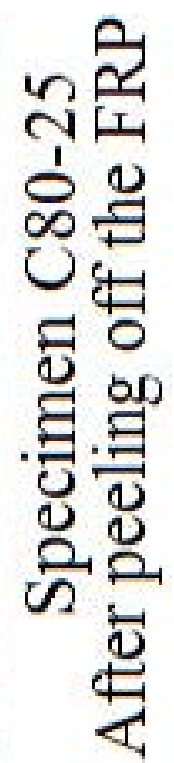
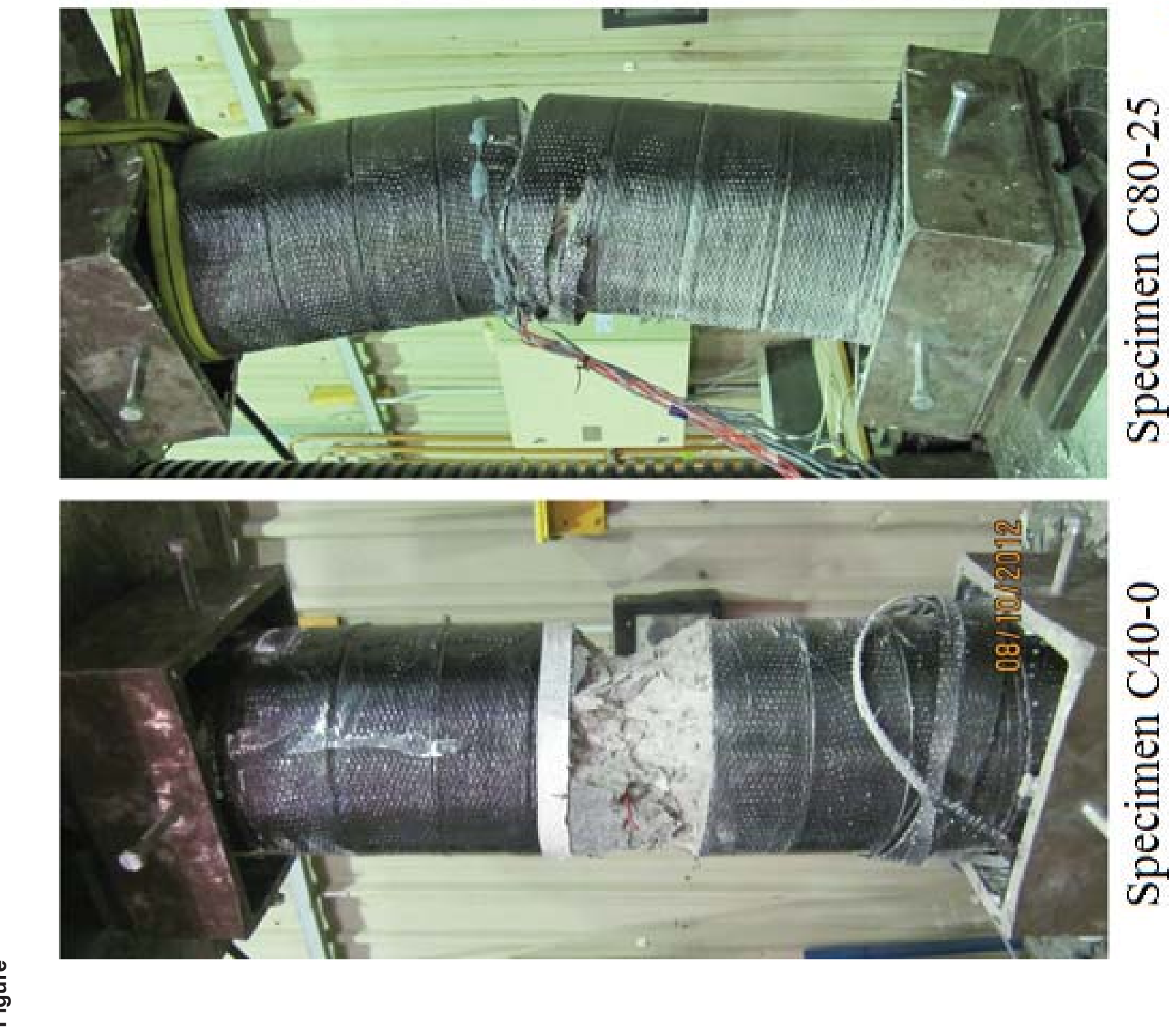


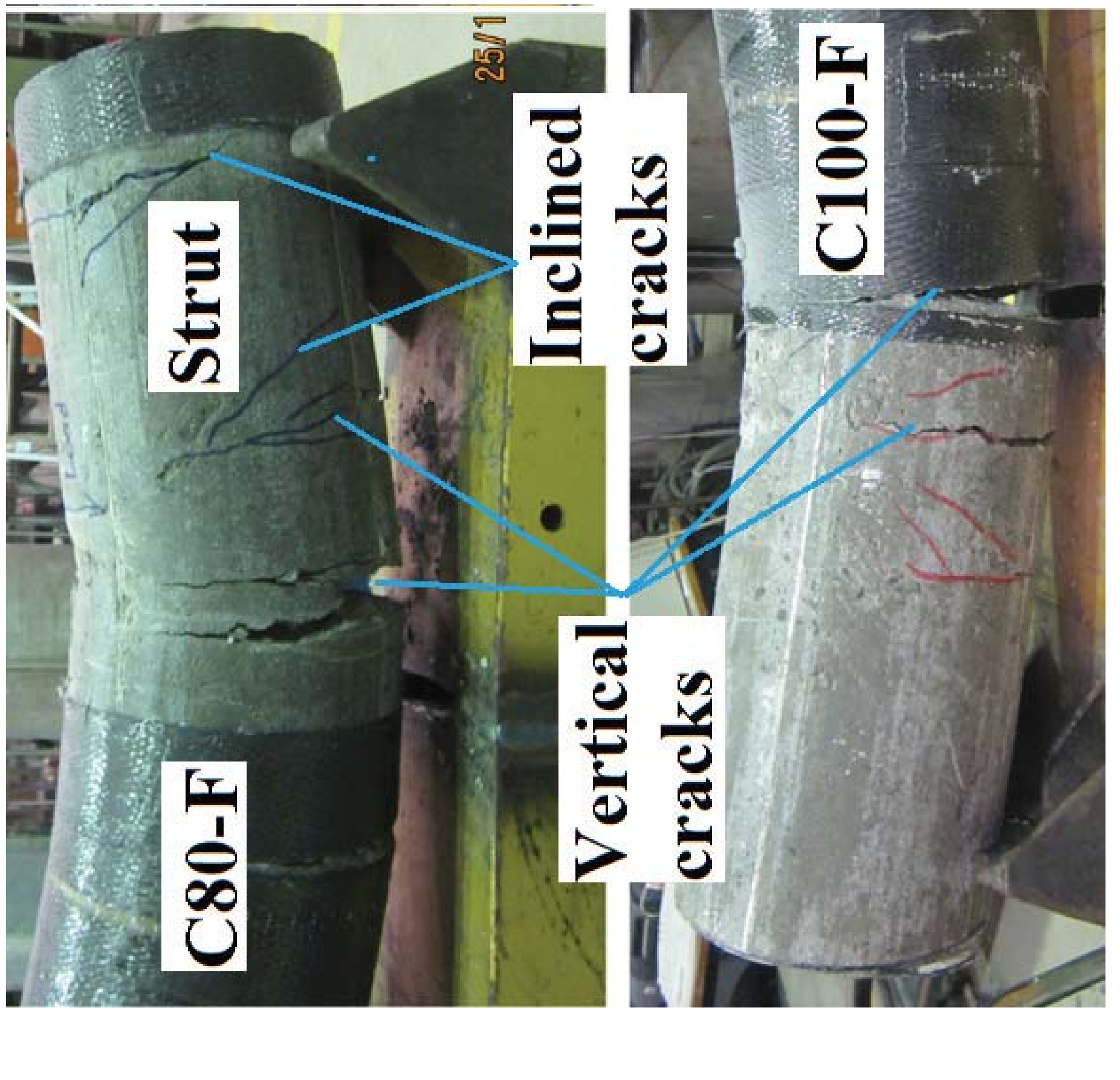




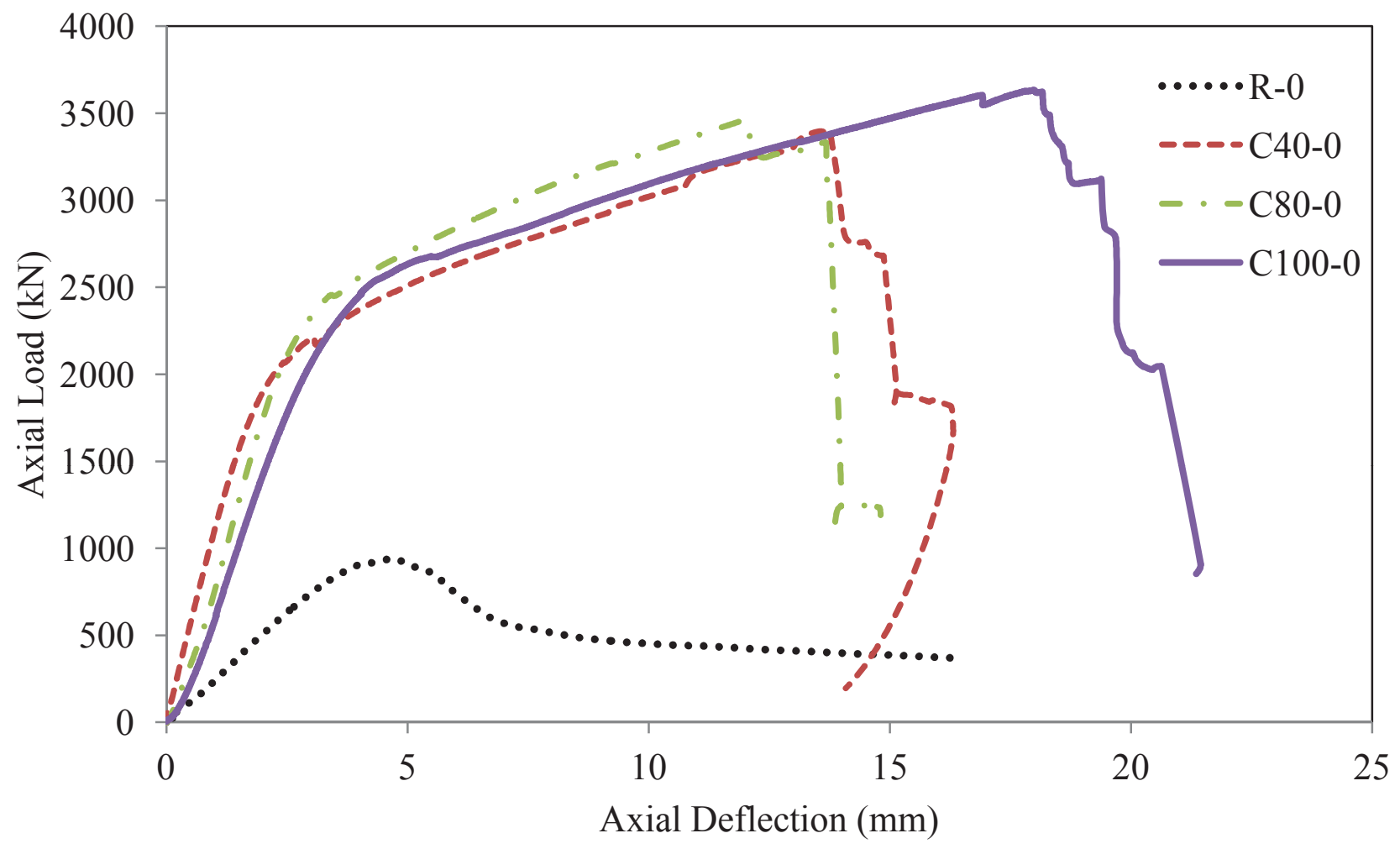




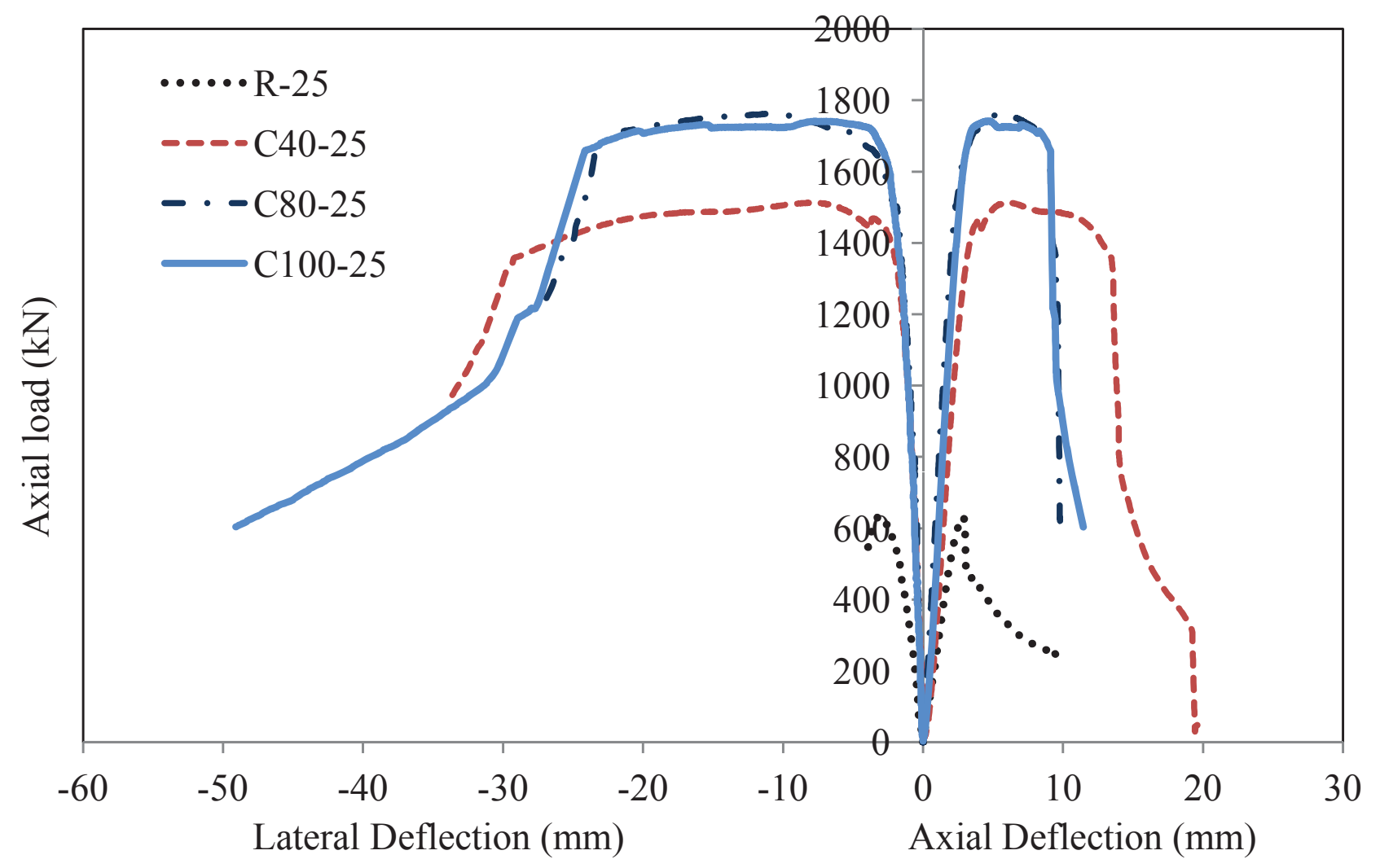




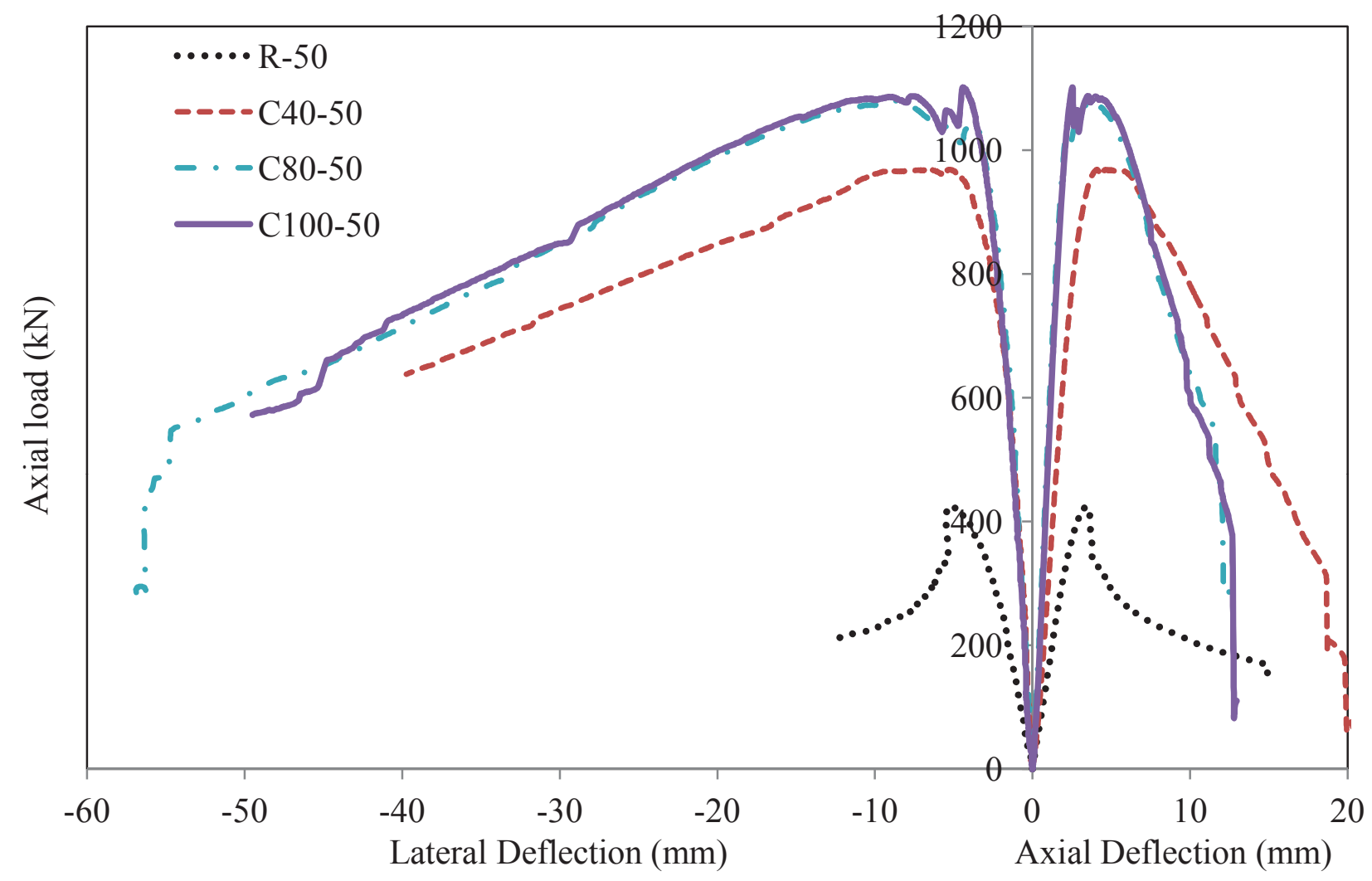




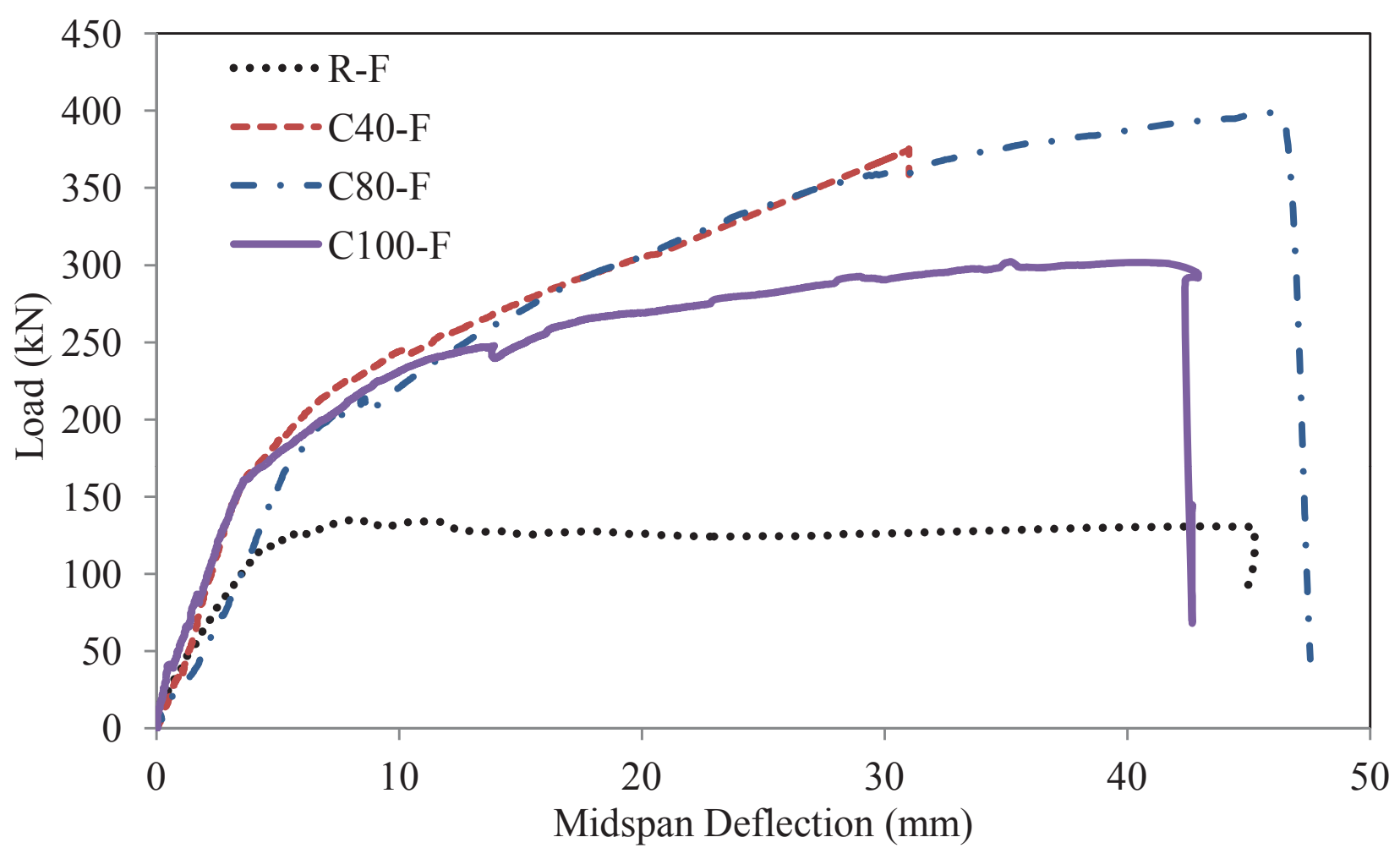




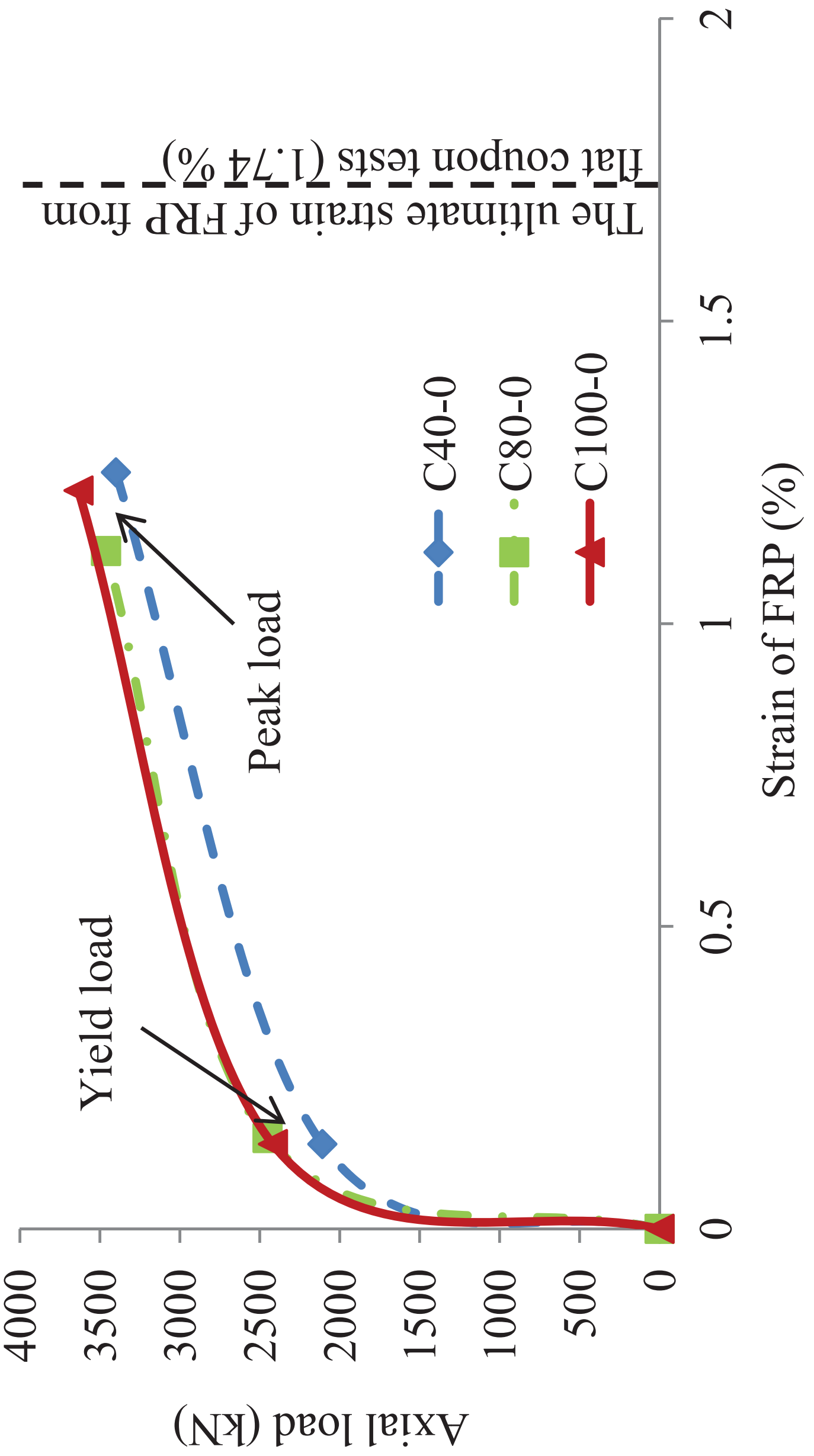




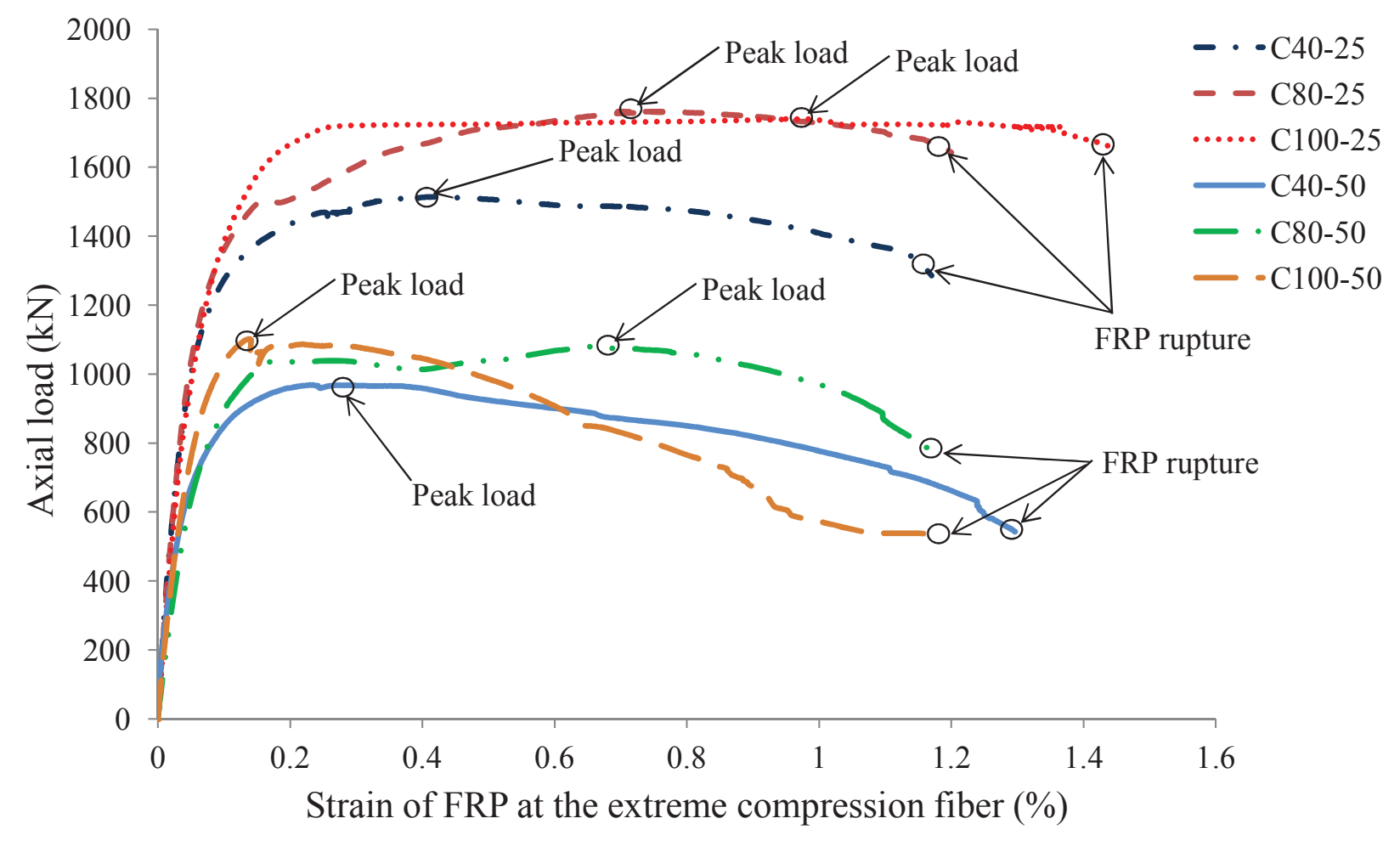



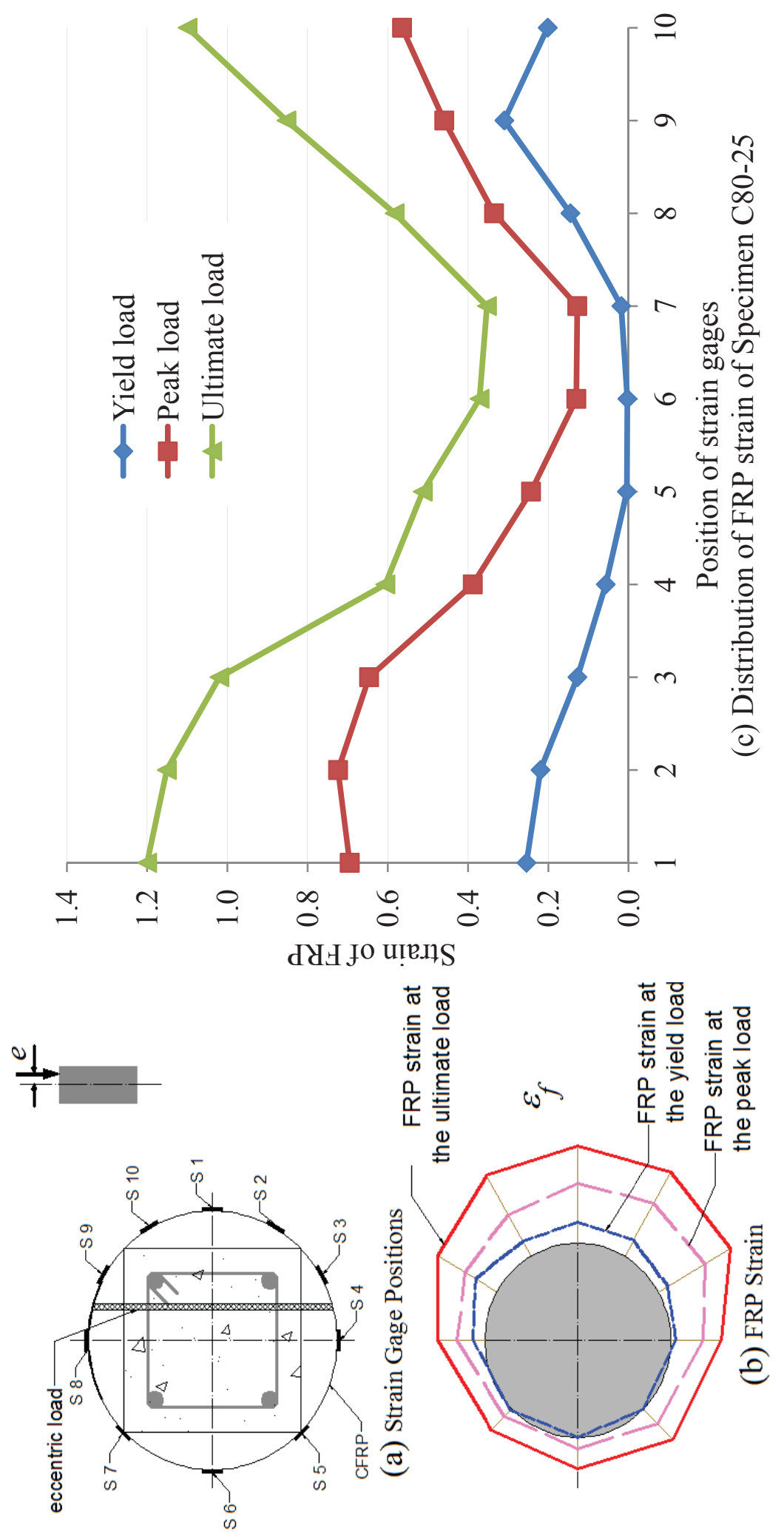


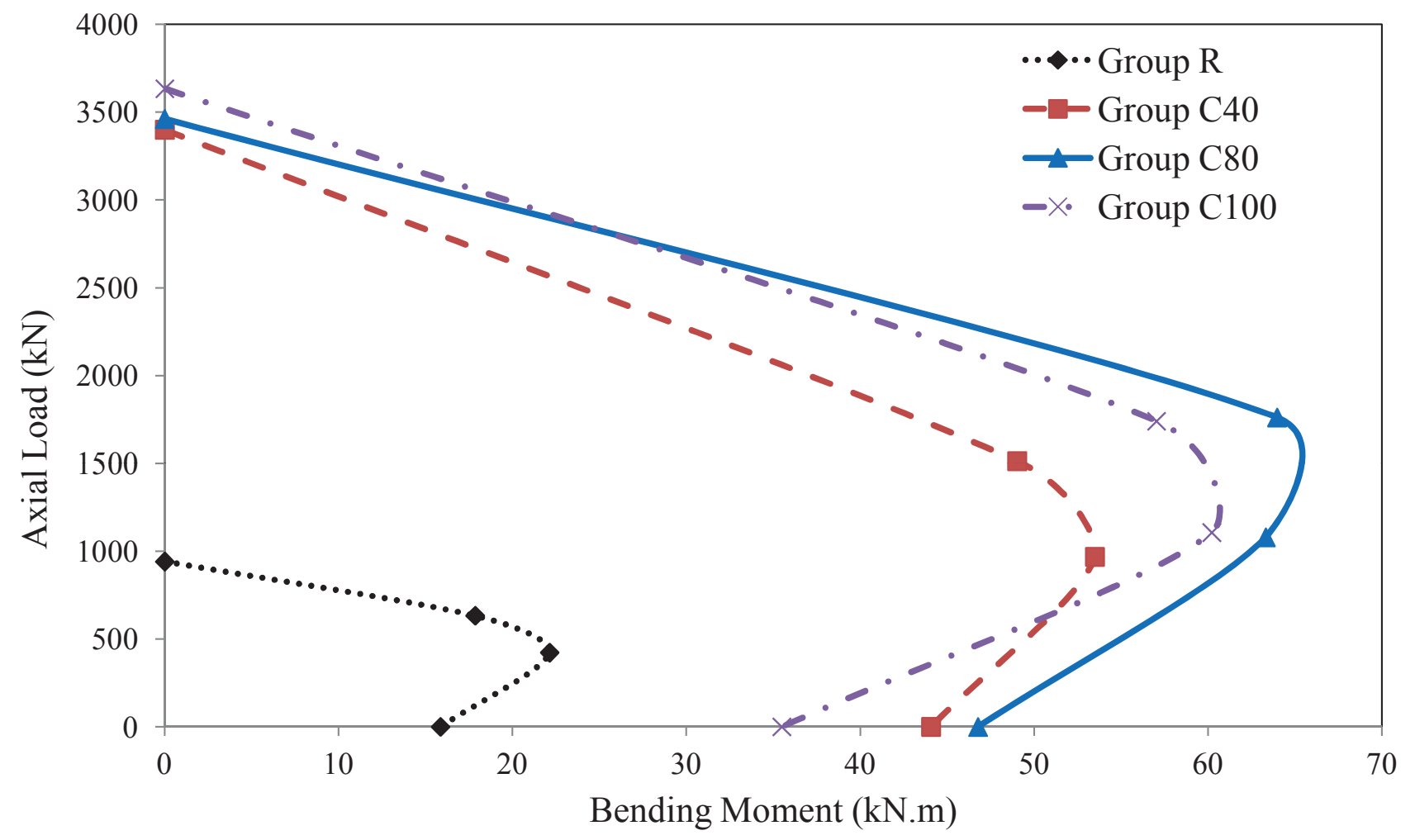




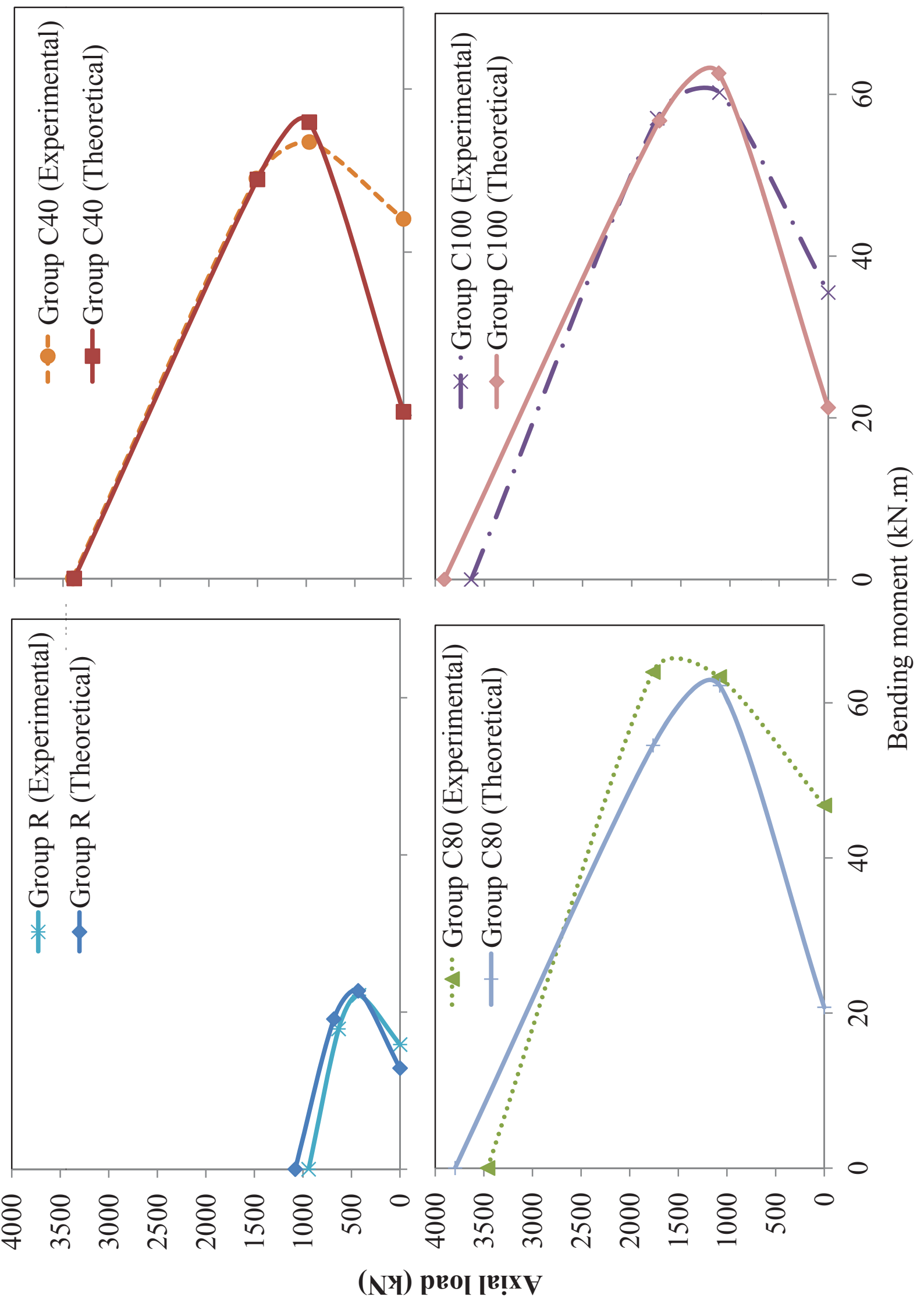

